\title{
Desemprego nas Macrorregiões do Brasil: uma Análise Comparativa dos Anos de 2014-2017
}

Unemployment in the Macro-regions of Brazil: a Comparative Analysis of the Years 20142017

\author{
Vicente Alves Toledo ${ }^{\mathrm{a}}$ \\ Diana Chaukat Chaib ${ }^{\mathrm{b}}$ \\ Ana Márcia Rodrigues da Silva ${ }^{c}$
}

\begin{abstract}
Resumo: O estudo trata do desemprego nas macrorregiões brasileiras entre 2014 e 2017. Seguindo a metodologia de decomposição adotada por Corseuil et al. (1997), analisa-se a participação de diferentes grupos populacionais e socioeconômicos no estoque de desempregados. Os principais resultados evidenciam que, diante do aumento do desemprego no Brasil de $6,8 \%$ para $12,7 \%$ no período analisado, os grupos dos homens, dos não jovens e não brancos aumentaram sua participação no contingente de desempregados.
\end{abstract}

Palavras-chave: Desemprego; Componentes; Macrorregiões do Brasil.

Classificação JEL: J2; J29; J82.

\begin{abstract}
The study refers to Brazilian macro-regions unemployment between 2014-2017. Following the decomposition methodology adopted by Corseuil et al. (1997), the participation of different population and socioeconomic groups in the unemployed people stock is analyzed. The main results evidence that, in face of the unemployment growth in Brazil from $6,8 \%$ to $12,7 \%$ in that period, the participation of the group of men, non-young people and non-white people increased in the unemployed people contingent.
\end{abstract}

Keywords: Unemployment; Components; Brazilian Macro-regions.

\footnotetext{
${ }^{a}$ Mestre em Economia pela Universidade Federal de Alfenas. E-mail: vicenteatoledo@gmail.com

${ }^{\mathrm{b}}$ Mestra em Economia pela Universidade Federal de Alfenas. E-mail: chaib.diana@ gmail.com

${ }^{\mathrm{c}}$ Professora Adjunta do Instituto de Ciências Sociais Aplicadas da Universidade Federal de Alfenas.

E-mail: anamarciarodrigues@gmail.com
} 


\section{Introdução}

O estudo do mercado de trabalho motiva debates no âmbito da Ciência Econômica. Segundo Ramos (2007), essa questão acompanha o nascimento da ciência e remonta as teorias dos mais antigos estudiosos. Nesse campo de pesquisa, as principais teorias podem ser divididas em duas principais abordagens. A primeira, de "natureza microeconômica", defende a ideia de que o funcionamento do mercado de trabalho é determinado na sua própria dinâmica, enquanto a segunda relaciona o comportamento desse mercado ao ritmo do crescimento da economia em geral (POCHMANN, 2015).

A discussão destacada acima e motivada na economia pode ser retratada, em termos gerais, da seguinte maneira: de um lado tem-se a Economia Clássica, defensora de que a economia estaria em um nível de pleno emprego, ou seja, a oferta de trabalho seria igual à demanda por trabalho. Nesse caso, a oferta de trabalho seria determinada pela quantidade de trabalhadores dispostos a trabalhar pelo salário real e, assim, o desemprego seria considerado voluntário. Por outro lado, Keynes questionou os pressupostos da Economia Clássica. $\mathrm{O}$ autor propunha que as pessoas estariam dispostas a trabalhar, porém os postos de trabalho seriam insuficientes para absorver todas elas. Devido à insuficiência dos postos de trabalho, o desemprego é tratado por Keynes como involuntário.

No campo teórico as diferentes maneiras de enxergar a problemática do desemprego implicam em divergências na explicação das suas causas e na indicação de políticas econômicas eficazes (SMITH, 2003). Empiricamente, verifica-se que as variações da taxa de desemprego acompanham as variações do nível de atividade econômica, em que o desemprego se torna um problema social de maior proporção em períodos de depressão econômica, tendendo a diminuir em períodos de crescimento econômico (PRONI, 2015).

Nesse sentido, quando um país sofre uma queda da produção é natural que as demissões cresçam em uma proporção maior do que as contratações. Isso faz com que trabalhadores percam empregos e que os novos ingressantes no mercado de trabalho não consigam possibilidades de trabalhar. O resultado desse movimento é a elevação da taxa de desemprego ${ }^{1}$. O que significa que o desemprego também está relacionado a questões conjunturais. Além destas, o desemprego e a segregação no mercado de trabalho estão relacionados a processos históricos e a opções de políticas (POCHMANN, 2009).

Em um cenário recente no Brasil metropolitano, a taxa de desemprego se manteve decrescente entre 2004 e 2014, apesar da crise deflagrada em 2008. O ano de 2015 pode ser visto como um ponto de inflexão no comportamento do mercado de trabalho. Isso indica que a trajetória de evolução do mercado de trabalho foi significativamente modificada, sendo marcada pelo crescimento vertiginoso do desemprego (POCHMANN, 2015).

\footnotetext{
${ }^{1} \mathrm{O}$ desemprego é representado pela parcela da população que está apta a trabalhar, que está em busca de um emprego, mas que não consegue encontrar postos de trabalho disponíveis. Assim, o desemprego é representado pelo número dos trabalhadores desempregados em relação à força de trabalho total. Segundo o Instituto Brasileiro de Geografia e Estatística (IBGE), a população economicamente ativa (PEA) é composta por pessoas em idade ativa (que tenham idade superior ou igual a 14 anos, segundo a definição da PNAD Contínua) e que estejam procurando por trabalho.
} 
Pochmann (2015) atribui esse aumento na taxa de desemprego ao impacto decisivo de políticas de ajuste econômico adotadas em pleno cenário de retração da economia nacional nos primeiros meses de 2015. A desaceleração observada na economia brasileira nesse período contribuiu tanto para o crescimento do endividamento público quanto para a diminuição da arrecadação tributária. Desse modo, o autor sustenta que o choque fiscal culminou em desajuste fiscal com recessão econômica, gerando relevantes repercussões sobre o mercado de trabalho.

Por meio de Proni (2015) tem-se a ideia de que a causa do desemprego pode variar de acordo o perfil dos desempregados sendo necessário investigar se o problema atinge a população de forma generalizada ou grupos mais vulneráveis. Entendimento muito importante quando se considera o elevado aumento do desemprego a partir de 2015 e que perdura até o presente.

Assim, tendo como referência o campo de estudo o qual este trabalho se insere e considerando o ressurgimento do desemprego como um grave problema social mediante sua atual elevação no Brasil, este artigo tem como objetivo analisar a mudança de participação de diferentes grupos populacionais e socioeconômicos no estoque de desempregados nas macrorregiões brasileiras. Considerando como ponto de partida o ano de 2014, período em que a taxa de desemprego atinge níveis mais baixos, e o ano de 2017, em que o desemprego retorna aos elevados níveis dos anos que antecedem 2004.

Para tanto, alicerçada nos dados da Pesquisa Nacional por Amostra de Domicílios Contínua (PNAD Contínua) seguiu-se uma metodologia de decomposição adotada por Corseuil et al. (1997), considerando as seguintes características demográficas e socioeconômicas: sexo, faixa etária, raça/cor e níveis de escolaridade. A decomposição permite identificar a alteração da participação desses grupos populacionais e socioeconômicos no estoque de desempregados, assim como os fatores do mercado de trabalho (oferta e/ou demanda) que contribuíram para essas mudanças.

O trabalho está estruturado desta maneira: após esta introdução, segue a $2^{\mathrm{a}}$ seção que é composta por uma breve apresentação da trajetória recente do desemprego no Brasil. Logo em seguida, na $3^{a}$ seção, tem-se a metodologia adotada na pesquisa. Os resultados e as considerações finais compõem, respectivamente, as $4^{\mathrm{a}}$ e $5^{\mathrm{a}}$ seções do trabalho.

\section{Trajetória Recente do Desemprego no Brasil}

Na década de 1990, os processos de abertura comercial e de reestruturação produtiva $^{2}$, inseridos em um contexto macroeconômico caracterizado por uma baixa taxa de crescimento do produto, trouxeram consigo a estagnação da capacidade de absorção de mão de obra pelo mercado de trabalho. Além disso, outras consequências puderam ser

\footnotetext{
${ }^{2}$ Almeida e Alencar apud Antunes (2000) definem que mudanças na organização produtiva implicam no reordenamento da produção e na acumulação com repercussões no mundo do trabalho, alterando processos e relações de trabalho, mediante inovações no sistema produtivo e nas modalidades de gestão, consumo e controle da força de trabalho.
} 
observadas como o avanço na desregulamentação das relações de trabalho e a ampliação do desemprego (IPEA, 2006; TONI, 2007).

Ainda nessa década, os impactos do Plano Real ${ }^{3}$ no mercado de trabalho foram desastrosos criando uma nova relação entre a dinâmica econômica e o emprego. Após sua implementação, foi observada uma contínua deterioração do nível de emprego, acompanhada por uma tendência sustentada de crescimento do desemprego (DEDECCA, 2005). No que se refere ao desemprego, é possível que o país tenha atingido, nessa década, patamares jamais alcançados antes (BASTOS, 2010).

$\mathrm{Na}$ década seguinte, o cenário é distinto. Ainda que até 2003 não se tenha uma trajetória muito nítida do mercado de trabalho do país, a partir de 2004 constata-se uma tendência mais clara no sentido de recuperação dos níveis de ocupação e da redução da incidência do desemprego. Esse desempenho esteve inserido em um contexto macroeconômico de maior crescimento do produto, recuperação dos investimentos e de incremento das exportações (BASTOS, 2010).

Nos anos posteriores, a economia brasileira se manteve nessa fase de expansão, diminuindo a taxa de desemprego para $10 \%$ em 2005 e para $8 \%$ em 2008. Além disso, é possível perceber diferenças marcantes entre as áreas metropolitanas brasileiras: o desemprego afeta uma proporção maior dos trabalhadores nas metrópoles do Nordeste e uma porcentagem menor da força de trabalho nas metrópoles do Sul (MORETTO; PRONI, 2011). Contudo, a crise econômica internacional de $2008^{4}$ interrompeu a trajetória de expansão da economia brasileira. Ocorreu uma recessão no primeiro semestre de 2009. Embora o PIB tenha sido menor em 2009 em relação a 2008 (-0,6\%), houve geração líquida de empregos com registro em vários ramos de atividade. Em 2011, as taxas confirmam a tendência de queda do desemprego (MORETTO; PRONI, 2011).

Em meados da década de 2010, especialmente a partir do final de 2014, a política econômica mudou de rumo, o que inverteu a trajetória do desemprego. Apesar da crise de dimensão global, deflagrada em 2008, a taxa de desemprego no Brasil se manteve decrescente entre 2004 e 2014, sobretudo com a adoção de uma política anticíclica. Já o ano de 2015 pode ser visto como um ponto de inflexão no comportamento do mercado de trabalho. Isso indica que a trajetória de evolução do mercado de trabalho foi significativamente modificada. Não só o desemprego volta a crescer rapidamente, como

\footnotetext{
${ }^{3}$ Programa brasileiro de estabilização econômica, criado em 1993 e implementado no ano seguinte, que visava promover o fim da inflação elevada no Brasil.

${ }^{4}$ A crise financeira internacional de 2008 foi originada pelas perdas causadas pelo crescente default dos empréstimos das hipotecas do mercado americano de Subprime, uma vez que grande parte dessas hipotecas havia sido securitizada e distribuída aos investidores do mercado global. Dessa forma, vemos que a crise foi resultado da desregulamentação das instituições do sistema financeiro e da falta de atuação regulamentadora, restritiva, do Estado. (DE PAULA; FERRARI FILHO, 2009)
} 
também o salário médio dos ocupados ${ }^{5}$ perdeu poder aquisitivo nos primeiros sete meses de 2015 (POCHMANN, 2015).

No mais, entre 2003 e 2013, cerca de cinco milhões de jovens postergaram o ingresso no mercado de trabalho após terem atingido 16 anos de idade. Na maior parte, a possibilidade de ampliar a escolaridade motiva a procura mais tardia por um emprego. Isso também explica a heterogeneidade do aumento do desemprego entre os trabalhadores (POCHMANN, 2015).

Assim, a queda no nível de atividade no ano de 2015 aparece somada à redução da quantidade de ocupados e do rendimento médio real recebido pelos trabalhadores. Diante dessa diminuição de renda, a tendência é que haja uma competição acirrada entre os trabalhadores gerada tanto por aqueles que perdem os empregos como pelos novos ingressantes no mercado de trabalho (POCHMANN, 2015).

Dada a noção acerca da trajetória do desemprego até 2015, é válido oferecer uma visão geral da evolução da taxa de desemprego no Brasil e nas macrorregiões no período em estudo - 2014 e 2017.

\section{Tabela 1: Evolução da taxa de desemprego em \% nas macrorregiões e no Brasil}

\begin{tabular}{c|c|c|c}
\hline \hline Macrorregiões & $\mathbf{2 0 1 4}$ & $\mathbf{2 0 1 7}$ & Variação ( $)$ \\
\hline Nordeste & 8,73 & 15,18 & $73,80 \%$ \\
\hline Norte & 7,15 & 12,53 & $75,34 \%$ \\
\hline Sudeste & 6,84 & 13,38 & $95,67 \%$ \\
\hline Sul & 4,12 & 8,31 & $101,75 \%$ \\
\hline Centro-Oeste & 5,54 & 10,41 & $87,94 \%$ \\
\hline Brasil & 6,82 & 12,73 & $86,75 \%$ \\
\hline \hline
\end{tabular}

Fonte: PNAD Contínua. Elaboração própria.

De acordo com a Tabela 1 , as maiores variações da taxa foram verificadas nas macrorregiões que apresentavam menor desemprego, Sul, Sudeste e Centro-Oeste. O Nordeste e o Norte experimentaram um menor aumento do desemprego no período em

\footnotetext{
${ }^{5}$ Indivíduos que, na semana de referência, exerceram trabalho remunerado naquela semana, assim como os que exerceram trabalho não remunerado durante pelo menos 15 horas naquele período, e ainda os que tinham trabalho remunerado, mas do qual estavam temporariamente afastados (RAMOS, 2007).
} 
relação às demais, apesar da primeira permanecer com o maior nível de desemprego no país. Um resultado dessas variações foi que o Sudeste passou a apresentar a segunda maior taxa de desemprego em 2017, posição ocupada pelo Norte em 2014. O Brasil apresenta uma taxa de $6,8 \%$ no ano de 2014, aumentando fortemente em 2017, ano que a taxa é $12,7 \%$.

\section{Metodologia}

Para atingir os objetivos propostos, foi realizada uma análise da participação dos grupos populacionais e socioeconômicos no estoque de desempregados das macrorregiões do Brasil: Norte, Nordeste, Centro-Oeste, Sudeste e Sul. Primeiramente, foram tabulados os dados com base nos microdados da Pesquisa Nacional por Amostra de Domicílios Contínua (PNAD Contínua), nos anos de 2014 e 2017. Depois, foram construídos os indicadores da composição do desemprego para as cinco macrorregiões do Brasil, com utilização do software Stata.

Para a análise das mudanças da composição do desemprego foram consideradas as características demográficas idade, sexo e raça/cor, o nível de escolaridade. Por idade, foram considerados jovens de 14 a 29 anos de idade e não jovens os indivíduos com idade maior que 29 anos. Sobre a raça/cor, a população foi dividida em dois grupos: brancos e não brancos, sendo este composto por indivíduos pretos e pardos. Os níveis de escolaridade foram fundamental incompleta, fundamental completa a média incompleta, média completa a superior incompleta e superior completa.

A metodologia utilizada nesta pesquisa foi adotada inicialmente por Corseuil et al. (1997) com dados da Pesquisa Mensal de Emprego (PME), em uma análise para as metrópoles brasileiras, no período entre 1986 e 1995. Assim, replicando esta metodologia para as macrorregiões do Brasil, temos que a participação de um grupo populacional no estoque de desempregados de uma região pode ser decomposta da seguinte forma:

$$
U_{i} / U=U_{i} / N_{i} \cdot N_{i} / P_{i} \cdot P_{i} / P . P / N . N / U
$$

$\mathrm{Na}$ qual, Ui representa o estoque de desempregados do grupo i; U, o estoque total de desempregados; Ni é o número de membros da PEA do grupo i; N o número de membros da PEA total; Pi é o número de membros da População em Idade Ativa (PIA) do grupo i; e por fim, $\mathrm{P}$ representa o número de membros da PIA total.

Para fins demonstrativos, a utilização desta fórmula para análise da participação do estoque de desempregados com ensino superior completo na região Nordeste é feita da seguinte forma: Ui representa o estoque de desempregados com ensino superior na região Nordeste; U, o estoque total de desempregados da região Nordeste; Ni é o número de pessoas com ensino superior na PEA da região Nordeste; $\mathrm{N}$, o número total de pessoas na PEA do Nordeste; Pi é o número de pessoas com ensino superior na PIA do Nordeste; e P, número total de pessoas na PIA do Nordeste.

A expressão (1) pode ser reescrita do seguinte modo: 


$$
U_{i} / U=\frac{U_{i} / N_{i}}{U / N} \cdot \frac{N_{i} / P_{i}}{N / P} \cdot \frac{P_{i}}{P}
$$

Pode-se transformar a expressão (1) na forma logarítmica para se obter os efeitos elasticidades de cada fator da decomposição sobre o desemprego, obtendo, dessa forma, a seguinte expressão:

$$
L_{n}\left(U_{i} / U\right)=\left[L_{n}\left(U_{i} / N_{i}\right)-L_{n}(U / N)\right]+\left[L_{n}\left(N_{i} / P_{i}\right)-L_{n}(N / P)\right]+L_{n}\left(P_{i} / P\right)
$$

A partir de (3) pode-se obter a decomposição em termos de variações, expressas a seguir:

$$
\Delta L_{n}\left(U_{i} / U\right)=\left[\Delta L_{n}\left(U_{i} / N_{i}\right)-\Delta L_{n}(U / N)\right]+\left[\Delta L_{n}\left(N_{i} / P_{i}\right)-\Delta L_{n}(N / P)\right]+\Delta L_{n}\left(P_{i} / P\right)
$$

Assim, por meio dessa expressão tem-se que a participação dos desempregados de um grupo i em uma determinada região depende de três fatores: da variação da taxa de desemprego do grupo $(\Delta \mathrm{Ln}(\mathrm{Ui} / \mathrm{Ni}))$ em relação à variação da taxa de desemprego da região $(\Delta \operatorname{Ln}(\mathrm{U} / \mathrm{N}))$, fator aqui denominado Componente I $([\Delta \operatorname{Ln}(\mathrm{Ui} / \mathrm{Ni})-\Delta \operatorname{Ln}(\mathrm{U} / \mathrm{N})])$; da variação da taxa de participação da força de trabalho do grupo $(\Delta \mathrm{Ln}(\mathrm{Ni} / \mathrm{Pi}))$ em relação a variação da taxa de participação da força de trabalho da região $(\Delta \operatorname{Ln}(\mathrm{N} / \mathrm{P}))$, representando o Componente II ( $[\Delta \mathrm{Ln}(\mathrm{Ni} / \mathrm{Pi})-\Delta \mathrm{Ln}(\mathrm{N} / \mathrm{P})])$; da variação da participação do grupo na PIA da região, o Componente III $(\Delta \mathrm{Ln}(\mathrm{Pi} / \mathrm{P}))$.

Com isso temos que, por exemplo, se no período em análise a taxa de desemprego de determinado grupo aumentar mais que a taxa de desemprego da região analisada, o Componente I contribuirá para o aumento da participação desse grupo no estoque de desempregados. Do mesmo modo, o Componente II contribuirá se a participação da PEA do grupo na PIA desse grupo aumentar mais que a participação da PEA total da região na PIA total dessa região. Em relação ao Componente III, segue-se a mesma ideia. É interessante notar que cada componente influencia separadamente de maneira positiva ou negativa a participação de um determinado grupo populacional ou socioeconômico no estoque de desempregados, sendo o efeito total sobre a participação, a conjugação da influência de cada componente.

Com isso, pode-se interpretar que o Componente I compreende pelo lado da demanda por trabalho as variações na participação de determinado grupo no contingente de desempregados, enquanto os componentes II e III compreendem essas variações pelo lado da oferta por trabalho. Vale dizer que o Componente III é característica puramente demográfica. 


\section{Resultados e Discussões}

Nesta seção são apresentados os resultados e as discussões pertinentes, sendo analisada a participação dos diferentes grupos populacionais no estoque de desempregados.

\section{Segmentação por sexo}

Conforme se pode observar, acontece uma diminuição generalizada da participação das mulheres no estoque de desempregados das macrorregiões do Brasil, na comparação de 2014 e 2017 (Tabela 2). Os declínios mais intensos do peso das mulheres no desemprego ocorreram na região Sul e Centro-Oeste. O componente I exerceu efeito no sentido de reduzir a participação feminina no estoque de desempregados de cada macrorregião, em que ocorre um aumento menos acelerado da taxa de desemprego desse grupo populacional em relação à taxa média de desemprego. Em relação aos demais componentes, esse fator impactou em maior magnitude a participação no desemprego. Ao analisar o componente III, vê-se que este exerceu forte efeito na redução da participação feminina no estoque de desempregados no Nordeste, que fora compensado pela contribuição positiva do componente II.

Tabela 2: Evolução da participação das mulheres no desemprego e seus componentes, entre 2014 e 2017, nas Macrorregiões do Brasil

\begin{tabular}{l|c|c|c|c}
\hline \hline Macrorregiões & $\begin{array}{c}\Delta \text { Participação no } \\
\text { desemprego }\end{array}$ & $\begin{array}{c}\text { Componente } \\
\text { I }\end{array}$ & $\begin{array}{c}\text { Componente } \\
\text { II }\end{array}$ & $\begin{array}{c}\text { Componente } \\
\text { III }\end{array}$ \\
\hline Nordeste & $-0,038$ & $-0,061167133$ & 0,592824263 & $-0,5698322$ \\
\hline Norte & $-0,039$ & $-0,075255483$ & 0,029398557 & 0,0072365 \\
\hline Sudeste & $-0,032$ & $-0,051458828$ & 0,026211205 & $-0,0065586$ \\
\hline Sul & $-0,051$ & $-0,059230646$ & 0,011635762 & $-0,0029401$ \\
\hline Centro-Oeste & $-0,041$ & $-0,067822341$ & 0,019265408 & 0,0070602 \\
\hline \hline
\end{tabular}

Fonte: PNAD Contínua. Elaboração própria.

Em decorrência das mudanças acima analisadas, houve um aumento da participação dos homens no contingente de desempregados das macrorregiões no período em foco (Tabela 3). A participação masculina no desemprego, em contrapartida dos movimentos assinalados entre as mulheres, aumentou com maior intensidade na região Sul. $\mathrm{O}$ componente I teve influência no sentido de aumentar a participação dos homens no 
desemprego para todas as macrorregiões. Já o componente II teve efeito no sentido de diminuir a participação desse grupo no estoque de desempregados para todas as macrorregiões.

Tabela 3: Evolução da participação dos homens no desemprego e seus componentes, entre 2014 e 2017, nas Macrorregiões do Brasil

\begin{tabular}{l|c|c|c|c}
\hline \hline Macrorregiões & $\begin{array}{c}\Delta \text { Participação no } \\
\text { desemprego }\end{array}$ & $\begin{array}{c}\text { Componente } \\
\text { I }\end{array}$ & $\begin{array}{c}\text { Componente } \\
\text { II }\end{array}$ & $\begin{array}{c}\text { Componente } \\
\text { III }\end{array}$ \\
\hline Nordeste & 0,0365 & 0,053428667 & $-0,017717766$ & 0,0007947 \\
\hline Norte & 0,0438 & 0,068704497 & $-0,017561963$ & $-0,0073904$ \\
\hline Sudeste & 0,0349 & 0,051038075 & $-0,023219074$ & 0,0070973 \\
\hline Sul & 0,0585 & 0,065551217 & $-0,010103331$ & 0,0030883 \\
\hline Centro-Oeste & 0,0489 & 0,069174244 & $-0,012788703$ & $-0,0075135$ \\
\hline \hline
\end{tabular}

Fonte: PNAD Contínua. Elaboração própria.

No que diz respeito aos resultados obtidos com a segmentação por sexo, observase que de maneira generalizada os homens aumentaram sua participação no estoque de desempregados enquanto as mulheres diminuíram sua participação. A evidência de que as mulheres recebem salários menores em relação aos homens pode auxiliar no entendimento da questão (RIBEIRO; DE JESUS, 2016; HOFFMAN; LEONE, 2009; RIBEIRO; SILVA ARAÚJO, 2016; DA ROCHA WEISHAUPT PRONI; PRONI, 2018). Esse resultado ocorreu com maior força na macrorregião Sul, seguida pelas Centro-Oeste, Norte, Nordeste e Sudeste. Para todas as macrorregiões o componente representativo da demanda por trabalho operou no sentido de diminuir a participação das mulheres no estoque de desempregados, em contrapartida, atuou no sentido de aumentar a participação dos homens no desemprego.

\section{Segmentação por Faixa Etária}

Como é apresentado na Tabela 4, ocorreu uma redução da participação dos jovens, de 14 a 29 anos, no estoque de desempregados em todas as macrorregiões brasileiras, entre 2014 e 2017. Essa redução ocorreu com maior intensidade na região Nordeste, e com menor, na região Sudeste. O Componente III, referente à participação da PIA jovem na PIA total da macrorregião, foi o fator que mais contribuiu para a redução desse grupo no desemprego das macrorregiões, exceto para o Sul. As taxas de desemprego da população jovem em todas as macrorregiões aumentaram menos que suas respectivas taxas médias de 
desemprego. Assim, o Componente I contribuiu de maneira generalizada para a redução dos jovens no estoque de desempregados.

Tabela 4: Evolução da participação dos jovens no desemprego e seus componentes, entre 2014 e 2017 - Macrorregiões do Brasil

\begin{tabular}{c|c|c|c|c}
\hline \hline Macrorregiões & $\begin{array}{c}\text { Participação no } \\
\text { Desemprego }\end{array}$ & $\begin{array}{c}\text { Componente } \\
\text { I }\end{array}$ & $\begin{array}{c}\text { Componente } \\
\text { II }\end{array}$ & $\begin{array}{c}\text { Componente } \\
\text { III }\end{array}$ \\
\hline Nordeste & $-0,093$ & $-0,03464262$ & 0,644779542 & $-0,7032493$ \\
\hline Norte & $-0,076$ & $-0,02057791$ & $-0,007836167$ & $-0,0478717$ \\
\hline Sudeste & $-0,053$ & $-0,02783033$ & 0,011272235 & $-0,0364321$ \\
\hline Sul & $-0,071$ & $-0,04706933$ & 0,00552635 & $-0,0297142$ \\
\hline Centro-Oeste & $-0,07$ & $-0,00751133$ & $-0,000781452$ & $-0,0616601$ \\
\hline \hline
\end{tabular}

Fonte: PNAD Contínua. Elaboração própria.

Contrariamente às mudanças observadas acima, em relação a população não jovem (maiores que 29 anos) ocorreu aumento da participação no estoque de desempregados para todas as macrorregiões (Tabela 5). Em destaque, esse aumento ocorreu com menor intensidade no Sudeste. Tem-se o Componente I e III, exceto para o Nordeste, contribuindo para o aumento da participação da população não jovem no desemprego das macrorregiões.

Tabela 5: Evolução da participação dos não jovens no desemprego e seus componentes, entre 2014 e 2017 - Macrorregiões do Brasil

\begin{tabular}{c|c|c|c|c}
\hline \hline Macrorregiões & $\begin{array}{c}\text { Participação no } \\
\text { Desemprego }\end{array}$ & $\begin{array}{c}\text { Componente } \\
\text { I }\end{array}$ & $\begin{array}{c}\text { Componente } \\
\text { II }\end{array}$ & $\begin{array}{c}\text { Componente } \\
\text { III }\end{array}$ \\
\hline Nordeste & 0,1186 & 0,091670454 & 0,648390369 & $-0,6214183$ \\
\hline Norte & 0,1113 & 0,083748475 & $-0,006461666$ & 0,0340011 \\
\hline Sudeste & 0,0651 & 0,054830633 & $-0,007816608$ & 0,0181008 \\
\hline Sul & 0,104 & 0,093616413 & $-0,004378102$ & 0,0147462 \\
\hline Centro-Oeste & 0,1011 & 0,073434533 & $-0,006435325$ & 0,0340704 \\
\hline \hline
\end{tabular}

Fonte: PNAD Contínua. Elaboração própria. 
Assim, no que se refere à segmentação por faixa etária da evolução da participação do estoque de desempregados entre 2014 e 2017, observa-se que diante do aumento do desemprego no Brasil no período, esse fenômeno atingiu em maior escala a população acima de 29 anos em todas as macrorregiões do país. Os jovens entre 14 a 29 anos diminuíram sua participação no desemprego ao passo que a população não jovem aumentou sua participação. Uma possível explicação para essa constatação pode ser uma maior preservação do emprego dos jovens considerando que recebem salários inferiores em relação aos não jovens (ARBACHE, 2000; GONÇALVES; DO MONTE, 2011). A região Sudeste experimentou essa variação com menor intensidade e o Nordeste com maior. Para os jovens de todo o país, o fator de demanda por trabalho contribui para a diminuição do peso do grupo no desemprego, enquanto o fator demográfico operou no sentido oposto.

\section{Segmentação por Raça/Cor}

Quando se observa a variável raça/cor, as evidências empíricas mostram a retirada de participação da população de raça/cor branca do desemprego (Tabela 6). A participação dos indivíduos dessa raça/cor diminuiu com maior intensidade no Nordeste. O componente I exerceu efeito no sentido de reduzir a participação desse grupo no estoque de desempregados de cada macrorregião onde ocorre aumento menos acelerado da taxa de desemprego desse grupo populacional em relação à taxa média de desemprego. $\mathrm{O}$ componente III, ao contrário da contribuição positiva do componente II, exerceu forte impacto nesse movimento de retirada do peso dos indivíduos de raça/cor branca no estoque de desempregados, com exceção da macrorregião Norte, onde ocorre o inverso.

Tabela 6: Evolução da participação segundo a raça/cor branca no desemprego e seus componentes, entre 2014 e 2017, nas Macrorregiões do Brasil

\begin{tabular}{l|c|c|c|c}
\hline \hline Macrorregiões & $\begin{array}{c}\Delta \text { Participação no } \\
\text { desemprego }\end{array}$ & $\begin{array}{c}\text { Componente } \\
\text { I }\end{array}$ & $\begin{array}{c}\text { Componente } \\
\text { II }\end{array}$ & $\begin{array}{c}\text { Componente } \\
\text { III }\end{array}$ \\
\hline Nordeste & $-0,115$ & $-0,101176697$ & 0,665519267 & $-0,6795018$ \\
\hline Norte & $-0,072$ & $-0,091056166$ & $-0,00195027$ & 0,0210128 \\
\hline Sudeste & $-0,098$ & $-0,036814867$ & 0,002895675 & $-0,0644529$ \\
\hline Sul & $-0,069$ & $-0,018989094$ & 0,000383667 & $-0,0501666$ \\
\hline Centro-Oeste & $-0,095$ & $-0,052202099$ & 0,005434098 & $-0,0479788$ \\
\hline \hline
\end{tabular}

Fonte: PNAD Contínua. Elaboração própria. 
A tabela 7 indica o grupo raça/cor não branca composto por indivíduos da cor preta e parda. Em sentido contrário do que foi evidenciado entre o grupo pertencente à raça/cor branca, o grupo dos indivíduos da raça/cor não branca aumentou sua participação no estoque de desempregados de maneira generalizada entre as macrorregiões analisadas no período em foco (Tabela 7). $\mathrm{O}$ aumento desse grupo no contingente de desempregados se dá com maior intensidade na região Sul. Vale ressaltar que isso se deve ao efeito do componente III, que exerce maior impacto entre os demais componentes. Desta forma, o que mais explica o aumento do grupo no estoque desempregados do Sul é o aumento relativo da PIA de raça/cor não branca na PIA total. Um fator que opera pelo lado da oferta no mercado de trabalho e puramente demográfico.

Tabela 7: Evolução da participação segundo a raça/cor não branca no desemprego e seus componentes, entre 2014 e 2017, nas Macrorregiões do Brasil

\begin{tabular}{l|c|c|c|l}
\hline \hline Macrorregiões & $\begin{array}{c}\Delta \text { Participação no } \\
\text { desemprego }\end{array}$ & $\begin{array}{c}\text { Componente } \\
\text { I }\end{array}$ & $\begin{array}{c}\text { Componente } \\
\text { II }\end{array}$ & $\begin{array}{c}\text { Componente } \\
\text { III }\end{array}$ \\
\hline Nordeste & 0,0276 & 0,025103589 & $-0,003703476$ & 0,0061806 \\
\hline Norte & 0,0113 & 0,021460734 & 0,000557491 & $-0,0106894$ \\
\hline Sudeste & 0,0805 & 0,01381367 & $-0,00147769$ & 0,0682108 \\
\hline Sul & 0,1541 & $-0,02821259$ & 0,005001158 & 0,1773489 \\
\hline Centro-Oeste & 0,0358 & 0,01508578 & $-0,002799507$ & 0,0235133 \\
\hline \hline
\end{tabular}

Fonte: PNAD Contínua. Elaboração própria.

Com os resultados obtidos pela segmentação por raça/cor destaca-se que no período de forte crescimento da taxa de desemprego entre 2014 e 2017 no Brasil, a população de cor/raça não branca aumentou sua participação no desemprego, ao mesmo tempo em que a população branca diminuiu sua participação. Em relação a esse resultado, aponta-se a necessidade de futuros estudos para explicá-lo, uma vez que envolve o aumento de participação no desemprego de um grupo historicamente mais vulnerável (RIBEIRO; SILVA ARAÚJO, 2016). A macrorregião Sul liderou esse aumento entre as demais, embora tal fato possa ser explicado em maior parte pelo forte impacto do componente demográfico sobre o peso do grupo no desemprego, superando a contribuição do fator de demanda por trabalho no sentido de diminuí-lo. 


\section{Segmentação por Escolaridade}

A participação dos indivíduos com escolaridade fundamental incompleta no estoque de desempregados aumentou no Nordeste, no Sul e no Centro-Oeste, e diminuiu no Norte e no Sudeste, não evidenciando um padrão definido da evolução da participação desse grupo no desemprego nas macrorregiões (Tabela 8). Esse aumento dos indivíduos com ensino fundamental incompleto no desemprego ocorreu com maior intensidade na macrorregião Centro-Oeste e teve o Componente I como o fator de maior impacto. Assim, no Nordeste, no Sul e no Centro-Oeste, as taxas de desemprego da população com escolaridade fundamental incompleta aumentaram mais que as taxas médias de desemprego, fato que teve maior contribuição para o assinalado aumento da participação desse grupo no estoque de desempregados. Exceto no Sudeste, os Componentes II e III tiveram impacto no sentido de diminuir o peso da população com ensino fundamental no desemprego nas macrorregiões.

Tabela 8: Evolução da participação dos indivíduos com escolaridade fundamental incompleta no desemprego e seus componentes, entre 2014 e 2017, nas Macrorregiões do Brasil

\begin{tabular}{l|c|c|c|c}
\hline \hline Macrorregiões & $\begin{array}{c}\Delta \text { Participação no } \\
\text { desemprego }\end{array}$ & $\begin{array}{c}\text { Componente } \\
\text { I }\end{array}$ & $\begin{array}{c}\text { Componente } \\
\text { II }\end{array}$ & $\begin{array}{c}\text { Componente } \\
\text { III }\end{array}$ \\
\hline Nordeste & 0,0259 & 0,102070979 & $-0,037383695$ & $-0,038762$ \\
\hline Norte & $-0,093$ & $-0,024504554$ & $-0,017491245$ & $-0,0505147$ \\
\hline Sudeste & $-0,057$ & 0,031692925 & 0,00210801 & $-0,0905992$ \\
\hline Sul & 0,0983 & 0,155255336 & $-0,025263218$ & $-0,0316467$ \\
\hline Centro-Oeste & 0,1225 & 0,180212997 & $-0,023639168$ & $-0,0341039$ \\
\hline \hline
\end{tabular}

Fonte: PNAD Contínua. Elaboração própria.

Os indivíduos com escolaridade fundamental completa a média incompleta apresentaram redução na participação no estoque de desempregados para as macrorregiões analisadas, exceto para o Sul (Tabela 9). Ainda com exceção dessa região, tem-se que os componentes II e III contribuíram de forma favorável à redução da participação desse grupo de indivíduos no contingente de desempregados. Vale ressaltar que a participação destes no desemprego diminuiu com maior intensidade no Centro-Oeste. O componente I contribui positivamente para a queda do peso desse grupo no estoque de desempregados, excetuando novamente, a região Centro-Oeste. 
Tabela 9 - Evolução da participação dos indivíduos com escolaridade fundamental completa a média incompleta no desemprego e seus componentes, entre 2014 e 2017, nas Macrorregiões do Brasil

\begin{tabular}{l|c|c|c|c}
\hline \hline Macrorregiões & $\begin{array}{c}\Delta \text { Participação no } \\
\text { desemprego }\end{array}$ & $\begin{array}{c}\text { Componente } \\
\text { I }\end{array}$ & $\begin{array}{c}\text { Componente } \\
\text { II }\end{array}$ & $\begin{array}{c}\text { Componente } \\
\text { III }\end{array}$ \\
\hline Nordeste & $-0,071$ & 0,003340467 & $-0,029034873$ & $-0,0452149$ \\
\hline Norte & $-0,056$ & 0,029535015 & $-0,024453247$ & $-0,0607235$ \\
\hline Sudeste & $-0,031$ & 0,050381331 & $-0,011553136$ & $-0,0702587$ \\
\hline Sul & 0,0006 & 0,062174696 & 0,023556623 & $-0,0851328$ \\
\hline Centro-Oeste & $-0,118$ & $-0,00321852$ & $-0,000951022$ & $-0,1142433$ \\
\hline \hline
\end{tabular}

Fonte: PNAD Contínua. Elaboração própria.

Em relação aos indivíduos com escolaridade média completa a superior incompleta houve, exceto para o Sul, aumento de participação no estoque de desempregados nas macrorregiões (Tabela 10). Isso ocorreu com menor intensidade no Centro-Oeste. Para todas as macrorregiões, a taxa de desemprego do grupo aumentou menos que a taxa média de desemprego total e a PIA do grupo perdeu peso na PIA total, sendo esse último fator o que mais contribuiu para o constatado aumento da participação desses indivíduos no desemprego.

Tabela 10 - Evolução da participação dos indivíduos com escolaridade média completa a superior incompleta no desemprego e seus componentes, entre 2014 e 2017, nas Macrorregiões do Brasil

\begin{tabular}{l|c|c|c|c}
\hline \hline Macrorregiões & $\begin{array}{c}\Delta \text { Participação no } \\
\text { desemprego }\end{array}$ & $\begin{array}{c}\text { Componente } \\
\text { I }\end{array}$ & $\begin{array}{c}\text { Componente } \\
\text { II }\end{array}$ & $\begin{array}{c}\text { Componente } \\
\text { III }\end{array}$ \\
\hline Nordeste & 0,0235 & $-0,07102401$ & 0,015613177 & 0,0788692 \\
\hline Norte & 0,0352 & $-0,02970370$ & $-0,010216106$ & 0,0750955 \\
\hline Sudeste & 0,033 & $-0,01257198$ & $-0,019227557$ & 0,0647567 \\
\hline Sul & $-0,053$ & $-0,07800362$ & $-0,01368911$ & 0,0385959 \\
\hline Centro-Oeste & 0,0054 & $-0,02208305$ & $-0,004593433$ & 0,0321154 \\
\hline \hline
\end{tabular}

Fonte: PNAD Contínua. Elaboração própria. 
Por fim, tem-se o grupo dos indivíduos com escolaridade superior completa (Tabela 11). Semelhante ao grupo analisado anteriormente, ocorre aumento da participação no estoque de desempregados das macrorregiões analisadas, porém aqui com a exceção do Centro-Oeste. A maior elevação foi verificada no Norte. Com restrição do Norte, a taxa de desemprego desse grupo aumentou menos que a taxa média de desemprego total. $\mathrm{O}$ componente II impactou no sentido de diminuir a participação desse grupo no estoque de desempregados, com ressalva da região Nordeste.

Tabela 11 - Evolução da participação dos indivíduos com escolaridade superior completa no desemprego e seus componentes, entre 2014 e 2017, nas Macrorregiões do Brasil

\begin{tabular}{l|c|c|c|c}
\hline \hline Macrorregiões & $\begin{array}{c}\Delta \text { Participação no } \\
\text { desemprego }\end{array}$ & $\begin{array}{c}\text { Componente } \\
\text { I }\end{array}$ & $\begin{array}{c}\text { Componente } \\
\text { II }\end{array}$ & $\begin{array}{c}\text { Componente } \\
\text { III }\end{array}$ \\
\hline Nordeste & 0,0768 & $-0,1259515$ & 0,022414391 & 0,1803386 \\
\hline Norte & 0,2859 & 0,03642213 & $-0,002651849$ & 0,252107 \\
\hline Sudeste & 0,0443 & $-0,053641705$ & $-0,030794265$ & 0,1287061 \\
\hline Sul & 0,0541 & $-0,087136332$ & $-0,024235861$ & 0,1654461 \\
\hline Centro-Oeste & $-0,007$ & $-0,197157087$ & $-0,033296298$ & 0,2234147 \\
\hline \hline
\end{tabular}

Fonte: PNAD Contínua. Elaboração própria.

Acerca dos resultados obtidos por meio da segmentação por escolaridade, de maneira geral, destaca-se a mudança do sentido do impacto do Componente I dos níveis baixos de escolaridade para os níveis mais altos. $\mathrm{O}$ fator que age pelo lado da demanda de trabalho é positivo para o grupo de indivíduos com escolaridade fundamental incompleta e também para os indivíduos de escolaridade fundamental completa a média incompleta, em quatro regiões. Torna-se negativo para o grupo de indivíduos de escolaridade média completa a superior incompleta, para todas as macrorregiões. E continua exercendo esse impacto para os indivíduos com escolaridade superior completa, no sentido de diminuir a participação do grupo no estoque de desempregados.

Nesse sentido, para quase todas as macrorregiões o componente de demanda por trabalho agiu no sentido de aumentar a participação do grupo de menor nível de escolaridade no desemprego e no sentido de diminuir a participação do grupo de maior nível de escolaridade no estoque de desempregados. Esse fato pode estar associado com os tipos de setores de atividade econômica que mais demitiram no período. Outra hipótese explicativa seria a opção de preservação dos mais escolarizados que podem ser realocados em outras posições ainda que com rendimentos inferiores. 


\section{Considerações Finais}

Tendo em vista o ressurgimento do desemprego como um grave problema social no período que compreende 2014 a 2017, o objetivo deste artigo foi fazer uma avaliação do desemprego nas macrorregiões do Brasil. Esta investigação pode ser importante para identificar as causas do desemprego, uma vez que o problema pode atingir a população como um todo ou a grupos mais vulneráveis, como descreve Proni (2015).

Por meio da metodologia inicialmente adotada por Corseuil et al. (1997), foi realizada uma análise da participação de grupos populacionais e socioeconômicos no estoque de desempregados das macrorregiões do Brasil: Norte, Nordeste, Centro-Oeste, Sudeste e Sul. Para a construção da composição do desemprego foram consideradas as seguintes características demográficas e socioeconômicas: sexo, raça/cor, faixa etária, e escolaridade.

O aumento do desemprego não se verifica de forma homogênea entre os trabalhadores brasileiros. Os resultados evidenciam que o aumento do desemprego no Brasil, de $6,8 \%$ para $12,7 \%$, entre 2014 e 2017 , atingiu mais a população não branca, os homens, e a população não jovem, que aumentaram suas participações no estoque de desempregados. Em relação a segmentação raça/cor, o movimento observado atenta para a macrorregião Sul, que experimentou o maior aumento de participação, bem explicado pela análise do impacto dos componentes. Já na análise por sexo o aumento de participação ocorre de maneira generalizada nas macrorregiões. No que tange a faixa etária, esse fenômeno acontece com maior intensidade no Nordeste.

Por meio da decomposição verificaram-se ainda os componentes mais significativos nas observadas mudanças de peso no estoque de desempregados. Essa identificação vem a contribuir para o reconhecimento das causas do desemprego apontando se as variações do peso de determinado grupo no desemprego foram mais impactadas por fatores que operam pelo lado da oferta e/ou da demanda por trabalho.

Com isso, pôde se constatar pela segmentação do estoque de desempregados por níveis de escolaridade que, em quase todas as macrorregiões, o componente da demanda por trabalho agiu no sentido de aumentar a participação do grupo de menor nível de escolaridade no desemprego, e agiu no sentido contrário em relação ao grupo com maior nível de escolaridade. Além disso, com esse tipo de análise evidenciou-se que, dentre as macrorregiões, o maior aumento de participação da população não branca no contingente de desempregados no Sul é explicado em maior parte por um fator puramente demográfico, qual seja, o aumento do peso da PIA de raça/cor não branca na PIA total da macrorregião. 


\section{Referências}

ANTUNES, R. Ensaio sobre as metamorfoses e a centralidade do mundo do trabalho. In: Adeus ao Trabalho. Editora da Universidade Estadual de Campinas, São Paulo, 2000. https://doi.org/10.1177/030981689906700109

ARBACHE, J. S. Determinação e diferencial de salários no Brasil. In: FONTES, R.; ARBEX, M. A. (Ed.). Desemprego e mercado de trabalho: ensaios teóricos e empíricos. Viçosa: UFV, 2000.

BASTOS, R. L. A. Desemprego metropolitano no Brasil: 1999-2007. Encontro Nacional da Associação Brasileira de Estudos Populacionais - ABEP. Anais, p. 1-21, 2010. https://doi.org/10.22456/2176-5456.16743

CORSEUIL, C. Determinantes da evolução da estrutura do desemprego no Brasil: 19861995. Economia Aplicada. São Paulo: USP, v. 1, n. 3, p. 443-467, 1997.

DA ROCHA WEISHAUPT PRONI, T. T.; PRONI, M. W. Discriminação de gênero em grandes empresas no Brasil. Estudos Feministas, v. 26, n. 1, p. 1-21, 2018.

http://dx.doi.org/10.1590/1806-9584.2018v26n141780

DEDECCA, C. S. Notas sobre a evolução do mercado de trabalho no Brasil. Revista de Economia política, v. 25, n. 1, p. 97, 2005. https://doi.org/10.1590/0101-35172005-1640

DE PAULA, L. F.; FERRARI FILHO, F. A crise das finanças desregulamentadas: o que fazer? Em: A crise financeira de 2008. Revista de Economia Política, vol. 29 nº 1 (113), pág 133- 149, Janeiro - Março, 2009.

GONÇALVES, M. F.; DO MONTE, P. A. A importância da experiência profissional na admissão e na disparidade salarial: um estudo para o mercado de trabalho formal do Nordeste. Revista Economia e Desenvolvimento, v. 10, n. 1, 2011.

HOFFMANN, R.; LEONE, E. T. Participação da mulher no mercado de trabalho e desigualdade da renda domiciliar per capita no Brasil: 1981-2002. Nova economia, v. 14, n. 2, 2009.

INSTITUTO BRASILEIRO DE GEOGRAFIA E ESTATÍSTICA - IBGE. Disponível em: <https://www.ibge.gov.br/> acesso em 13 Agosto.

INSTITUTO DE PESQUISA ECONÔMICA APLICADA. Brasil: o estado de uma nação. Brasília: IPEA, 2006.

KEYNES, J. M. (1936). A Teoria Geral do Emprego, do Juro e do Dinheiro. Col. Os Economistas. Ed. Abril, São Paulo, 1977.

MORETTO, A. J.; PRONI, M. W. O desemprego no Brasil: análise da trajetória recente. Revista Economia e Desenvolvimento, v. 10, n. 2, 2011. 
POCHMANN, M. O trabalho na crise econômica no Brasil: primeiros sinais. Estudos avançados, v. 23, n. 66, p. 41-52, 2009. https://doi.org/10.1590/S010340142009000200004

POCHMANN, M. Ajuste econômico e desemprego recente no Brasil metropolitano. Estudos Avançados, v. 29, n. 85, p. 7-19, 2015. https://doi.org/10.1590/S010340142015008500002

RAMOS, L. O desempenho recente do mercado de trabalho brasileiro: tendências, fatos estilizados e padrões espaciais. Ipea: Texto para Discussão, n. 1.255, 2007.

RIBEIRO, R. M.; DE JESUS, R. S. A inserção da mulher no mercado de trabalho no Brasil. Revista de Ciências Humanas, v. 15, n. 1, 2016.

RIBEIRO, R.; SILVA ARAÚJO, G. Segregação ocupacional no mercado de trabalho segundo cor e nível de escolaridade no Brasil contemporâneo. Nova Economia, v. 26, n. 1, 8 ago. 2016. https://doi.org/10.1590/0103-6351/2652

SMITH, S. Labour Economics. 2. ed. London, UK: Routledge, 2003.

TONI, M. Precarização do trabalho a partir dos anos 90: reversão da tendência no período recente? In: BASTOS, R. (Coord.). Dimensões da precarização do mercado de trabalho da Região Metropolitana de Porto Alegre. Porto Alegre: Convênio FEE, FGTAS/SINE-RS, DIEESE, SEADE-SP, MTE/FAT e apoio PMPA, 2007. 